\title{
3-NITROPROPIONIC ACID AND SIMILAR NITROTOXINS
}

\author{
Jiři Patočka, Jiři Bielavský, Jiř́i Cabal, Josef Fusek
}

Purkyně Military Medical Academy, Hradec Králové: Department of Toxicology

Summary: 3-Nitropropionic acid as well as 3-nitro-1-propanol and its $\beta$-D-glucopyranoside (miserotoxin) are the plant and fungal toxins reported to interrupt mitochondrial electron transport resulting in cellular energy deficit. These nitrotoxins induce neurological degeneration in ruminants and humans. 3-Nitropropionic acid-intoxicated rats serve as the animal model for Huntington's disease.

Key words: Plant toxin; Fungal toxin; Nitrotoxin; 3-nitropropionic acid; Miserotoxin; Milkvetch

\section{Introduction}

The nitrotoxins, 3-nitropropionic acid, 3-nitro-1-propanol and 3-nitro-1-propyl- $\beta$-D-glucopyranoside called miserotoxin, were found in many leguminous plants. These compounds are toxic principle of various milk vetches (Astragalus spp.) that are distributed worldwide. These poisonous plants are often a reason of intoxication of cattle, sheep, and horses in the United States and Canada (33,49,50). 3-Nitropropionic acid is sometimes produced on moldy crops as for example sugarcane or peanuts in amounts sufficient to cause severe neurological disorders when consumed by humans (45,39). 3-Nitropropionic acid is produced by the fungus Arthrinium spp. (6). Many synthetically prepared nitro-compounds have also considerable toxicity to both invertebratea and vertebratea, but because these compounds are not natural origin, there are not the aim of this article.

\section{Chemistry}

3-Nitropropionic acid, is white solid, m.p. $65-68{ }^{\circ} \mathrm{C}$, soluble in water $\left(0.1 \mathrm{~g} / \mathrm{ml} \mathrm{H}_{2} \mathrm{O}\right)$, ethanol, ether and chloroform, insoluble in petroleum. Dissociation exponent $(\mathrm{pK})=$ 3.79 at $25{ }^{\circ} \mathrm{C}$. 3-Nitro-1-propanol, liquid of density 1.21 $\mathrm{g} / \mathrm{cm}^{3}$ is an aglycone of miserotoxin. Miserotoxin, 3-nitro-1propyl- $\beta$-D-glucopyranoside (I) is native compound in many plants of spp. Astragalus.

3-Nitropropionic acid was prepared for the first time by Lewkovitsch (J.Prakt. Chem.20, 169, 1879) by reaction of sodium salt of 3-iodopropionic acid with sodium nitrite. Free form of 3-nitropropionic acid is easy available by reaction of 3-iodopropionic acid with $\mathrm{AgNO}_{2}$ and is very stabile (63).

Oehrlein et al. (43) prepared 3-nitro-1-propanal by 1,4nitrite addition to acrolein and described several acetals of 3-nitro-1-propanal, as well as 3-nitro-1-propanol and some of its ethers. 3-Nitro-1-propanol has been obtained by borane-dimethylsulfide reduction of both 3-nitro-1-propanal and 3-nitropropionic acid.

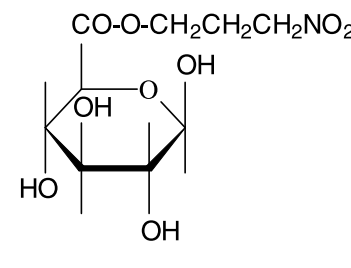

I<smiles>OC1CN2CCCC(O)C2C1O</smiles>

II

\section{Biological effects}

\section{Mitochondrial toxin and inhibitor of succinate dehydrogenase}

Mitochondria produce most of energy in animal cells by a process called oxidative phosphorylation. At this procedure electrons are passed along a series of respiratory enzyme complexes located in the inner mitochondrial membrane, and the energy released by this electron transfer is used to pump protons across the membrane. The resultant electrochemical gradient enables another complex, ATP-synthase, to synthesize the energy carrier ATP (55). 3-Nitropropionic acid irreversible inactivates succinate dehydrogenase (SDH) in mitochondria and caused a defect in cellular energy metabolism and is called as mitochondrial toxin $(2,20)$. SDH is inactivated in all cells, but very important is mainly inhibition of SDH in neurons, because it is connected with some mitochondrial diseases and with mitochondrial encephalomyopathies (22,51). After 3-nitropropionic acid administration to animals the SDH activity 
was reduced according to a similar time-course, most prominently in the cerebellum and least sharply in the thalamus. Activity of SDH remained significantly reduced in most areas of brain, except thalamus, for up to five days after dosing (47). Serial 1H-NMR spectroscopy study in primates shows that 3-nitropropionic acid-induced SDH inhibition following systematic injection similarly affects all brain regions $(21)$.

\section{Hypothermia}

The administration of 3-nitropropionic acid to animals leads to hypothermia. A single dose of 3-nitropropionic acid in dose $30 \mathrm{mg} / \mathrm{kg}$ s.c. to adult male Sprague-Dawley rats experienced a progressive hypothermia, which reached a loss of $3{ }^{\circ} \mathrm{C}$ or more in core body temperature by 3 hours after dosing (21). Hypothermic effect is connected with mitochondrial blockade of succinate dehydrogenase and reduction of cellular energy (54).

\section{Animal model of Huntington's disease}

Huntington's disease (HD) is a neurodegenerative disorder characterized by selective loss of neurons in the basal ganglia. Although the gene defect connected with mitochondrial dysfunction has recently been identified (28, 56 ), the mechanism by which it leads to neuronal degeneration remains unknown. It was hypothesized that a defect in oxidative phosphoprylation may lead to slow, excitotoxic neuronal degeneration in this illness. It is well known that the neuronal function and survival depend on a continuous supply of glucose and oxygen, used to generate ATP through glycolysis and mitochondrial respiration, as well as that a perturbation in energy metabolism during conditions such as ischemia and brain trauma may cause irreversible neuronal injury (65). An age-related decline in energy metabolism also may contribute to neuronal loss during normal aging, as well as in neurodegenerative diseases (8). Recent studies with 3-nitropropionic acid have shown that it can produce striking similarities to the neuropathologic and neurochemical features of HD in both rodents and primates (30). If such a mechanism is indeed relevant to the pathogenesis of HD, the agents that can improve oxidative phosphorylation might prove to be efficacious. It was found that both coenzyme $Q_{10}$ and nicotinamide can ameliorate striatal lesions produced by mitochondrial toxins in vivo (7).

Previous studies in primates have shown that chronic systemic administration of the 3-nitropropionic acid replicates most of the motor, cognitive, and histopathological features of one neurodegenerative disease, HD (19). In HD, uncontrollable involuntary movements, psychiatric abnormalities and a loss of intellectual functions (dementia) are the three major manifestations. Involuntary movements, such as chorea, result from abnormalities in basal ganglia which are located deep in the brain and regulate motor mo- vements. One of these structures called striatum shows a decreased volume in HD. The atrophy is due to degeneration of a particular subpopulation of the neurons called medium-size spiny neurons located within the striatum (17). Dementia and psychiatric abnormalities are due to degeneration of neurons outside the basal ganglia. A loss of neurons in the cerebral cortex is particularly prominent in Alzheimer's disease. The mechanism of the degeneration is not fully understood, but there is not doubt that 3-nitropropionic acid is an indirect excitotoxin (67). It has been also demonstrated that it exacerbates N-methyl-D-aspartate toxicity and this synergism may be relevant to the neuronal death observed in neurodegenerative dosorders (29). Fukuda et al. (26) demonstrated that astrocytes are more vulnerable than neurons to 3-nitropropionic acid-induced cellular $\mathrm{Ca}^{2+}$ overload and toxicity.

The morphological and histochemical effects of 3-nitropropionic acid were examined in cultured murine embryonal carcinoma cells. This compound caused a dose-dependent inhibition of cell proliferation at concentrations above $1.05 \mathrm{mM}$ and was lethal at 4.2 mM. Morphological changes included gross swelling of the cells, swelling of mitochondria and accumulation of organellar debris within the cytoplasm. 3-Nitropropionic acid inhibited succinate dehydrogenase but not of malate, isocitrate or glucose-6-phosphate dehydrogenases, resulting in a decrease in intracellular ATP (45).

\section{Neurotoxicity}

3-Nitropropionic acid-intoxicated rats frequently serve as the animal model for HD $(53,57)$. This acid can be characterized as excitotoxic compound and impaired mitochondrial energy component which produced lesions in the striatum, hippocampus, and corpus callosum but not in the cortex $(7,9,19)$. Excitotoxic effect of 3-nitropropionic acid is different from excitotoxic effect of quinolinic acid (52). Frim et al. (24) have found that nerve growth factor, delivered biologically by the implantation of a genetically altered fibroblast cell-line, can protect locally against striatal degeneration induced by infusions of high doses of glutamate receptor agonists and reduced the size of adjacent striatal 3-nitropropionic acid lesions. The role of the glutamatergic system in the convulsant action of 3-nitropropionic acid was studied in mice by Urbanska et al. (62). The occurence of 3-nitropropionic acid-induced seizures was inhibited by the $\alpha$-amino-2,3-dihydro-5-methyl-3-oxo-isoxazole-propionate (AMPA)/kainate receptor antagonists, 6nitro-7-sulphamoylbenzo[f]quinoxaline-2,3-dione disodium (NBQX) and 1-(4-aminophenyl)-4-methyl-7,8-methylenedioxy-5H-2,3-benzodiazepine (GYKI 52466). Motor deficits and striatal neuron degeneration produced by systemic 3-nitropropionic acid administration may be protected by 2amino-6-trifluoromethoxy-benzothiolate (Riluzole) (31). Riluzole is a glutamate release inhibitor $(35,36)$ which is used clinically in patients with amyotrophic lateral sclerosis (64). 
Systemic administration of 3-nitropropionic acid produced lateral striatal, hippocampal CA1 and CA3 lesions in the rat brain (60). Behrens et al. (11) found that 3-nitropropionic acid produces gradual neuronal degeneration characterized by cell body shrinkage and DNA fragmentation. Addition of glutamate antagonists during 3-nitropropionic acid exposure did not reduce neuronal death. However, addition of the macromolecular synthesis inhibitors cycloheximide, emetine or actinomycin D markedly reduced neuronal death. Their results do not exclude that 3-nitropropionic acid can induce excitotoxicity in more intact systems, but raise the additional possibility that this nitrotoxin may also act to induce neuronal apoptosis. Pang and Geddes (44) found that in cultured rat hippocampal neurons, 3-nitropropionic acid-induced cell death occurs through two distinct pathways. One involves activation of the NMDA receptor, which leads to a rapid necrotic death. The other is a delayed, apoptotic death, which is independent on N-methyl-D-aspartate (NMDA) receptor activation $(23,59,66)$. Bonfocco et al. (16) before now demonstrated that glutamate-induced cell death could be either apoptotic or necrotic depending on the intensity of stimuli or the ability of neurons to recover mitochondrial membrane potential (5) and Boireau et al. (15) demonstrated that 3-nitropropionic acid exacerbates GABA release evoked by glucose deprivation in rat brain slices. It is uncertain whether the presumed apoptosis did indeed result from glutamate receptor activation or merely reflected background apoptosis (1,61). Moderate levels of extracellular glutamate shift the cell death pathway from apoptosis to necrosis. It seems to be excitotoxicity that may display both apoptic and necrotic features (48).

\section{Animal toxicity}

Many milk vetches are toxic for animals and cattle. Horses and sheep have also been poisoned. Poisoning results in pulmonary emphysema and spinal cord demyelinization, commonly occurs in cattle. Milk vetch toxins act quickly with most animals that ingest lethal doses. They die in 4 to 24 hours, but more often, animals die within 3 or 4 hours after eating the plant. One $\mathrm{kg}$ of green milk vetch may be a lethal dose for a $500-\mathrm{kg}$ cow. These acutely poisoned animals generally show severe respiratory distress and muscular weakness progressing to paralysis such that affected animals fall after the slightest excitement. The heart rate is often extremely high. Although animals appear bright, they quickly die. The exact cause of death in this case has not been determined, but it is thought to be caused by fatal cardiovascular effects of nitrotoxins. It is true, that in some species of Astragalus, for example Astragalus bisulcatus or A. lentiginosus, whose growth in Canada, also other very toxic chemical, indolizidine alkaloid swainsonine (II) was observed, which cause locoism in cattle, horse, and sheep (40) and it is not challenged that biological effects of nitrotoxins and swainsonine may be cumulated. Swain- sonine also causes teratogenic deformities in lambs, calves, and goals (18)

Chronic intoxication most often occur in cattle and sheep from grazing any of the toxic varieties of nitrotoxincontaining Astragalus species slowly over a period of several days or weeks. Poisoned animals have respiratory problems, rapid respiration and as intoxication progresses, respiration develops a wheezing or roaring sound. These animals develop extensive pulmonary emphysema and demyelinization of the posterior spinal cord. When forced to move rapidly, animal may collapse and die.

The toxicity of miserotoxin in rats after peroral administration is low and $\mathrm{LD}_{50}$ is more than $2.5 \mathrm{~g} / \mathrm{kg}$ but 3-nitro1-propanol is at least 30 times more toxic $\left(\mathrm{LD}_{50}=77\right.$ $\mathrm{mg} / \mathrm{kg}$ ) (38). Extensive toxicity of misorotoxin for cattle is caused by the fact, that miserotoxin is quickly hydrolyzed to 3-nitro-1-propanol in the rumen of cattle (38).The nitrocompounds 3-nitro-1-propanol and 3-nitropropionic acid were shown to be equally toxic when injected intraperitoneally into male Wistar rats. The $\mathrm{LD}_{50}$ for 3-nitro-1-propanol was $0.58 \mathrm{mmol} / \mathrm{kg}(60 \mathrm{mg} / \mathrm{kg})$ and for 3-nitropropionic acid it was $0.56 \mathrm{mmol} / \mathrm{kg}(67 \mathrm{mg} / \mathrm{kg})(48)$.

\section{Behavioral toxicity}

The behavioral effects of a single subcutaneous injection of both 3-nitro-1-propanol and 3-nitropropionic acid dissolved in saline solution were studied in mice and rats, respectively. Clinical signs included depression, abnormal motor activity, and recumbency (27). No differences between 3-nitro-1-propanol and 3-nitroproiponic acid were observed.

The SDH activity, demonstrated histochemically in frozen brain section, was markedly reduced in intoxicated mice and rats but the changes in activity of another mitochondrial flavoprotein enzyme, $\alpha$-glycerophosphate dehydrogenase, was not observed.

\section{Natural sources}

Nitrotoxins were found in many species and varieties of Astragalus plants. The most important poisonous plants are different species of milk vetches, whose grow throughout much of North America. Commonly widespread strain, the meadow milk vetch (Astragalus diversifolius) is given on Fig. 1. Most of the poisonous species grow on the meadows, deserts, and forests in the Rocky Mountain States. Milk vetches emerge from late April to June, depending on elevation and snowmelt. As plants mature and dry, they decrease in toxicity until they are nontoxic when they are dry. The loss of toxicity may be due to newly observed specific oxidase that catalyses the oxygen-dependent oxidation of 3nitropropionic acid to malonate, semialdehyde, nitrate and nitrite (32). Recently nitrotoxins were found also in plants of spp. Astragalus which growth in Europe (59). The poisonous substance in milk vetches is the $\beta$-D-glucoside of 3nitro-1-propanol, called miserotoxin (I). This compound is 
hydrolysed to its aglycon, more toxic 3-nitro-1-propanol, in a stomach of ruminants (69), and this compound is further metabolized to 3-nitropropionic acid (41). A bacterium capable of metabolizing 3-nitro-1-propanol and 3-nitropropionic acid has been isolated from a mixed ruminal population (3). This ruminal bacterium was characterized as nonmotile gram-positive bacterium which not produce spores (4). The biotransformation of 3-nitro-1-propanol to 3-nitropropionic acid via 3-nitropropanal was also implemented in vitro by horse liver alcohol dehydrogenase (12).

Fig. 1: Meadow milkvetch (Astragalus diversifolius var. diversifolius).

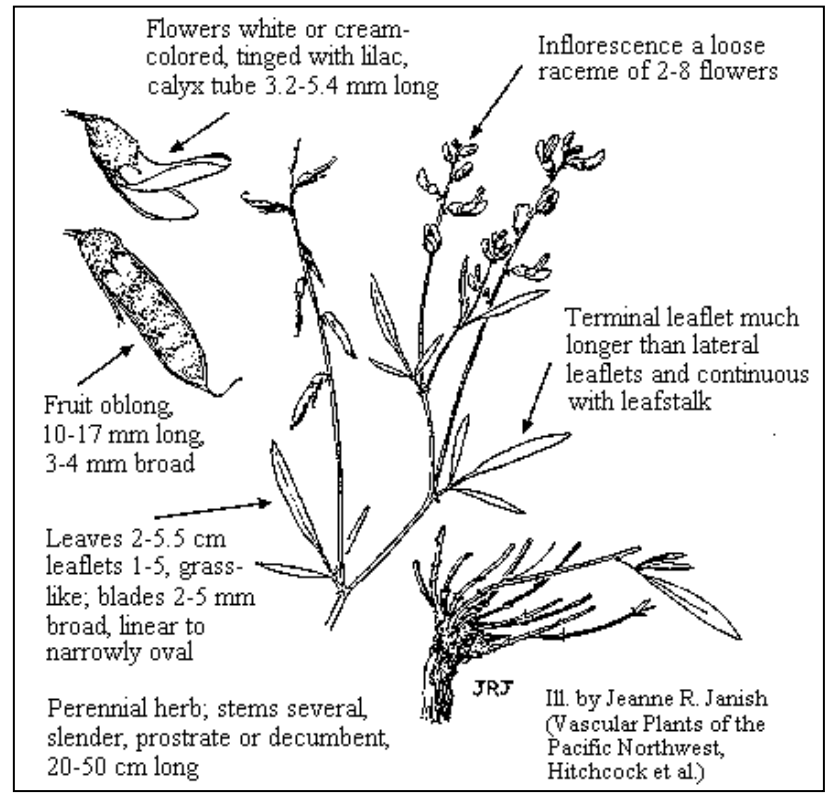

\section{Hazard for humans}

We found also some information about human toxicity of reviewed nitrotoxins. Moldy sugarcane poisoning, an acute fatal food poisoning of unknown etiology, has occurred in 13 provinces in China. The epidemiological characteristics and clinical features were described. Evidence from laboratory studies indicates that 3-nitropropionic acid produced by the fungus Arthrinium spp. is the etiological factor of this food poisoning (36). The biosynthesis of 3-nitropropionic acid is probably realized by enzymic decarboxylation of L-nitrosuccinate (6). Ingestion of 3-nitropropionic acid in moldy sugar cane causes brain damage in children. As has been account previously, the mechanism of 3-NPA toxicity is thought to be inhibition of energy production, leading to ATP depletion and excitotoxicity (12). Beal et al. (10) reported that the marker of hydroxyl radical production was attenuated in $\mathrm{CuZn}$-superoxide dismutase transgenic mice. Additionaly, recent studies have suggested involvement of reactive oxygen species and oxidative stress in the 3-nitropropionic acid induced neurotoxicity $(13,14$, 25,68).

From this information and from the accidental animal intoxications as well as from the mechanism of their toxic action we can concluded that both 3-nitro-1-propanol and 3nitropropionic acid represent very dangerous compounds with high degree of hazard for human being (47). Since the preparation of these compounds in laboratory is not overwhelming problem (43), we must consider 3-nitro-1-propanol as well as 3-nitropropionic acid to be potentially misuse toxic compounds with deadly effect.

\section{Conclusions}

Both 3-nitropropionic acid and 3-nitro-1-propanol are the most important representatives of nitrotoxins, which are toxic principles of many leguminous plants. Namely plants of some Astragalus spp. contain considerable amount of these toxins and there are often a reason of intoxication of cattle, sheep, and horses. Nitrotoxins have deadly effect and may be very dangerous for human being, too.

This study was supported by the grant of Ministry of Defense, project CEP MO 6602129911.

\section{References}

1. Alexi T, Hughes PE, Knusel B, Tobin AJ. Metabolic compromise with systemic 3-nitropropionic acid produces striatal apoptosis ins Sprague-Dawley rats but not in BALB/c ByJ mice. Exp Neurol 1998;153:74-93.

2. Alston TA, Mela L, Bright HJ. 3-Nitropropionate, the toxic substance of Indiofera, is a suicide inactivator of succinate dehydrogenase. Proc Natl Acad Sci USA 1977; 74:3767-71.

3. Anderson RC, Rasmussen MA, Allison MJ. Enrichment and isolation of a nitropropanol-metabiolizing bacterium from the rumen. Appl Environ Microbiol 1996;62:3885-6.

4. Anderson RC, Rasmussen MA, Di Spirito AA, Allison MJ. Characteristics of a nitropropanol-metabolizing bacterium isolated from the rumen. Can J Microbiol 1997;43:617-24.

5. Ankarcrona M, Dypbukt JM, Bonfoco E, Zhivotovski B, Orrenius S, Lipton SA, Nicotera P. Glutamate-induced neuronal death: a succession of necrosis or apoptosis depending on mitochondrial function. Neuron 1995;14:961-73.

6. Baxter RL, Smith SL, Martin JR, Hanley AB. The Fungal Biosynthesis of 3Nitropropionic Acid: Is the Decarboxylation of L-Nitrosuccinate an Enzymatic Reaction? J Chem Soc Perkin Trans I 1994;16:2297-300.

7. Beal MF. Neurochemistry and toxin models of Huntingtons's disease. Curr Opin Neurol 1994; 7:542-7.

8. Beal MF. Aging, energy, and oxidative stress in neurodegenerative diseases. Ann Neurol 1995;38:357-66.

9. Beal MF, Brouillet E, Jenkins BG et al. Neurochemical and histologic characterization of striatal excitotoxic lesions produced by the mitochondrial toxin 3-nitropropionic acid. J Neurosci 1993;13:4181-92.

10. Beal MF, Ferrante RJ, Henshaw R et al. 3-Nitropropionic acid neurotoxicity is at tenuated in copper/zinc dismutase transgenic mice. J Neurochem 1995;65:91922 .

11. Behrens MI, Koh J, Canzoniero LM, Sensi SL, Csernansky CA, Cchoi DW. 3Nitropropionic acid induces apoptosis in cultured striatal and cortical neurons. Neuroreport 1995;6:545-8.

12. Benn MH, McDiarmid RE, Majak W. In vitro biotransformation of 3-nitropropanol (miserotoxin aglycone) by horse liver alcohol dehydrogenase. Toxicol Lett 1989;47:165-72.

13. Binienda Z, Kim CS. Increase in levels of total free fatty acids in rat brain regions following 3-nitropropionic acid administration. Neurosci Lett 1997;230:199-201.

14. Binienda Z, Simmons C, Hussain S, Slikker W, Jr., Ali SF. Effect of acute exposure to 3-nitropropionic acid on activities of endogenous antioxidants in the rat brain. Neurosci Lett 1998;251:173-6. 
15. Boireau A, Meunier M, Doble A. 3-Nitropropionic acid exacerbates $\left({ }^{3} \mathrm{H}\right) \mathrm{GABA}$ release evoked by glucose deprivation in rat striatal slices. J Pharm Pharmacol 1996;48:85-9.

16. Bonfoco E, Krainc D, Ankarcrona M, Nicotera P, Lipton SA. Apoptosis and necrosis: two distinct events induced, respectively, by mild and intense insult with $\mathrm{N}$ methyl-D-aspartate or nitric oxide/superoxide in cortical cell cultures. Proc Natl Acad Sci USA 1995;92:7162-6.

17. Brouillet E, Conde F, Beal MF, Hantraye P. Replicating Huntington's disease phenotype in experimental animals. Prog Neurobiol 1999;59:427-68.

18. Cheeke PR, Shull LR. Natural Toxicants in Feeds and Poisonous Plants. AVI Publ Comp Inc, Westport, USA, 1985, pp. 492.

19. Chyi T, Chang C. Temporal evolution of 3-nitropropionic acid-induced neurodegeneration in the rat brain by T2-wighted, diffusion-weighted, and perfusion magnetic resonance imaging. Neuroscience 1999;92:1035-41.

20. Coles CJ, Edmondson DE, Singer TP. Inactivation of succinate dehydrogenase by 3-nitropropionic acid. J Biol Chem 1979;254:5161-7.

21. Dautry C, Conde F, Brouillet E et al. Serial 1H-NMR spectroscopy study of metabolic impairment in primates chronically treated with the succinate dehydrogenase inhibitor 3-nitropropionic acid. Neurobiol Dis 1999;6:259-68.

22. Di Mauro S, Moraes CT. Mitochondrial encephalomyopathies. Arch Neurol 1993;50:1197-208.

23. Fink SL, Ho DY, Sapolsyk RM. Energy and glutamate dependency of 3-nitropropionic acid neurotoxicity in culture. Exo Neurol 1996;138:298-304

24. Frim DM, Simpson J, Uhler TA et al. Striatal degeneration induced by mitochondrial blockade is prevented by biologically delivered NGF. J Neurosci Res 1993;35:452-8

25. Fu Y, He F, Zhang S, Zhang J. Lipid peroxidation in rats intoxicated with 3-nitropropionic acid. Toxicon 1995:33:327-31.

26. Fukuda A, Deshpande SB, Shimano Y, Nishino H. Astrocytes are more vulnerable than neurons to cellular $\mathrm{Ca}^{2+}$ overload induced by a mitochondrial toxin, 3nitropropionic acid. Neuroscience 1998;87:494-507.

27. Gould DH, Wilson MP, Hamar DW. Brain enzyme and clinical alternations induced in rats and mice by nitroaliphatic toxicants. Toxicol Lett 1985;27:83-9.

28. Graeber MB, Muller U. Recent developments in the molecular genetics of mitochondrial disorders. J Neurol Sci 1998;153:251-63

29. Greene JG, Sheu SS, Gross RA, Greenamyre JT. 3-Nitropropionic acid excacerbates $\mathrm{N}$-methyl-D-aspartate toxicity in striatal culture by multiple mechanisms. Neuroscience 1998;84:503-10.

30. Guyot MC, Hantrye P, Dolan R, Palfi S, Maziére M, Brouillet E. Quantifiable bradykinesia, gait abnormalities nad Huntington's disease-like striatal lesions in rat chronically treated with 3-nitropropionic acid. Neuroscience 1997;70:45-56.

31. Guyot MC, Palfi S, Stutzmann JM, Maziére M, Hantrye P, Brouillet E. Riluzole protects from motor deficits and striatal degeneration produced by systemic 3 nitropropionic acid intoxication in rats. Neuroscience 1997;81:141-9

32. Hipkin CR, Salem MA, Simpson D, Wainwright SJ. 3-Nitropropionic acid oxidase from horseshoe vetch (Hippocrepis comosa): a novel plant enzyme. Biochem J 1999;340:491-5

33. Kirkpatrick JG, Burrows GI Locoism in horses. Vet Hum Toxicol 1990;32:168-9.

34. Koh JY, Kim DK, Hwang JY, Kim YH, Seo, JH. Antioxidative nad proapoptotic effects of riluzole on cultured cortical neurons. J Neurochem 1999;72:716-23.

35. Kretschmer BD, Kratzer U, Schmidt WJ. Riluzole, a glutamate release inhibitor, and motor behavior. Naunyn Shiedbergers Arch Pharmacol 1998;358:181-90.

36. Liu X, Luo X, Hu W. Studies on the epidemiology and etiology of moldy sugarcane poisoning in China. Biomed Environ Sci 1992;5:161-77.

37. Majak W, Pass MA, Madryga FJ. Toxicity of miserotoxin and its aglycone (3nitropropanol) to rats. Toxicol Lett 1983;19:171-8.

38. Majak W, Pass MA, Muir AD, Rode LM. Absorption of 3-nitropropanol (miserotoxin aglycone) from the compound stomach of cattle. Toxicol Lett 1984;23:915.

39. Ming L. Moldy sugarcane poisoning - a case report with a brief review. J Toxicol Clin Toxicol 1995;33:363-7.

40. Molyneux RJ, James LF. Loco intoxication: indolizidine alkaloids of spotted locoweed (Astragalus lentiginosus). Science (Wash) 1982;216:190-1.

41. Muir AD, Majak W, Pass MA, Yost GS. Conversion of 3-nitropropanol (miserotoxin aglycone) to 3-nitropropionic acid in cattle and sheep. Toxicol Let 1984;20:137-41.

42. Nony PA, Scallet AC, Rountree RL, Ye X, Binienda Z. 3-Nitropropionic acid (3NPA) produces hypothermia and inhibits histochemical labeling of succinate dehydrogenase (SDH) in rat brain. Metab Brain Dis 1999;14:83-94.

43. Oehrlein R, Schwab W, Ehrler R, Jaeger V. 3-Nitropropanal and 3-nitropropanol: preparation of the parent compounds and derivatives. Synthesis 1986;7:535-8.

44. Pang Z, Geddes JW. Mechanisms of cell death induced by the mitochondrial toxin 3-nitropropionic acid: Acute excitotoxic necrosis and delayed apoptosis. J Neurosci 1997:17:3064-73.

45. Pass MA, Carlise CH, Reuhl KR. 3-Nitropropionic acid toxicity in cultured murine embryonal carcinoma cells. Nat Toxins 1994;2:386-94.
46. Pass MA, Muir AD, Majak W, Yost GS. Effect of alcohol and aldehyde dehydrogenase inhibitors on the toxicity of 3-nitropropanol in rats. Toxicol Appl Pharmacol 1985;78:310-15.

47. Peraica M, Radic B, Lucic A, Pavlovic M. Toxic effects of mycotoxins in humans. Bull World Health Organ 1999;77:754-66.

48. Portera-Cailliau C, Hedreen JC, Price DL, Koliatsos VE. Evidence for apoptotic cell death in Huntington disease and excitotoxic animal models. J Neurosci 1995:15:3775-87.

49. Ralphs MH, James LF, Nielsen DB, Baker DC, Molyneus RJ. Cattle grazing Wahweap Milkvetch in southeastern Utah. J Anim Sci 1988;66:3124-30.

50. Ralphs MH, Panter KE, James LF. Feed preferences and habituation of sheep poisoned by Locoweed. J Anim Sci 1990;68:1354-62.

51. Reichmann H, Janetzky B, Klinge M, Riederer P. Parkinson disease - a mitochondrial myopathy? (Article in Germany). Nervenartz 1993;64:215-20.

52. Reynolds NC, Jr, Lin W, Cameron CM, Roerig DL. Differential responses of extracellular GABA to intrastriatal perfusions of 3-nitropropionic acid and quinolinic acid in the rat. Brain Res 1997:778:140-9.

53. Reynolds NC, Jr, Lin W, Cameron CM, Roerig DL. Extracellular perfusion of rat brain nuclei using microdialysis: a method for studying differential neurotransmitter release in response to neurotoxins. Brain Res Brain Res Protoc 1999:4:124

54. Riepe M, Hori N, Ludolph AC, Carpenter DO, Spencer PS, Allen CN. Inhibition of energy metabolism by 3-nitropropionic acid activates ATP-sensitive potassium channels. Brain Res 1992;586:61-6.

55. Saraste M. Oxidative phosphorylation at the fin de siecle. Science 1999;283:148893.

56. Shapira AH. Mitochondrial dysfunction in neurodegenerative disorders. Biochim Biophys Acta 1998;1366:225-33.

57. Shear DA, Dong J., Gundy CD, Haik-Creguer KL, Dunbar GL. Comparison of intrastriatal injections of quinolinic acid and 3-nitropropionic acid for use in animal models of Huntington's disease. Progr Neuro-Psychopharmacol Biol Psych 1998;22:1217-40

58. Simpson DJ, Wainwright SJ, Hipkin CR. Presence of 3-nitropropionic acid in widely distributed pasture legumes in Britain. Vet Rec 1999;145:169-71.

59. Sugino I, Nozaki K, Takagi Y, Hashimoto N. 3-Nitropropionic acid induces ischemic tolerance in gerbil hippocampus in vivo. Neurosci Lett 1999;259:9-12.

60. Sugino I, Nozaki K, Takagi Y, Hashimoto N, Yodoi J. Expression and distribution of redox regulatory protein, thioredoxin after metabolic impairment by 3-nitropropionic acid in rat brain. Neurosci Lett 1999w;275:145-8.

61. Sugino T, Nozaki K., Tokime T, Hashimoto N, Kikuchi H. 3-Nitropropionic acid induces poly(ADP-ribosyl)ation and apoptosis related gene expression in the striatum in vivo. Neurosci Lett 1997;237:121-4.

62. Urbanska EM, Blaszczak P, Saran T, Kleinrok Z, Turski WA. AMPA/Kainate-related mechanisms contribute to convulsant and preconvulsant effects of 3-nitropropionic acid. Eur J Pharmacol 1999;370:251-6.

63. Votoček E. Chemie organická. Second edition. Vol. I. Praha:Politika, 1927, p. 346.

64. Wagner ML, Landis BE. Riluzole: a new agent for amyotrophic lateral sclerosis. Ann Pharmacother 1997;31:738-44.

65. Wallace DC. Mitochondrial DNA mutations in diseases of energy metabolism. J Bioenerg Biomembr 1994;26:241-50.

66. Weih M, Bergk A, Isaev NK et al. Induction of ischemic tolerance in rat cortical neurons by 3-nitropropionic acid: chemical preconditioning. Neurosci Lett 1999:272:207-10

67. Weller M, Paul SM. 3-Nitropropioic acid is an indirect excitotoxin to cultured cerebellar granule neurons. Eur J Pharmacol 1993;248:223-8.

68. Wiegand F, Lindauer U, Busch C, Liao W, Megow D, Dirnagl U. Tolerance to fo$\mathrm{cal}$ ischemie induced by 3-NPA is mediated by formation of reactive oxygen species. Soc Neurosci Abstr 1998;23:2183.

69. Williams MC, Norris FA, Van Kampen KR. Metabolism of miserotoxin to 3-nit ro-1-propanol in bovine and ovine ruminal fluids. Am J Vet Res 1970;31:259-62.

Submitted December 1999.

Accepted March 2000

Prof. RNDr. Jiř́ Patočka, DrSc., Purkyně Military Medical Academy, Department of Toxicology, 50001 Hradec Králové, Czech Republic. e-mail: patocka@pmfhk.cz 